Article

\title{
High-Efficiency Isolated Photovoltaic Microinverter Using Wide-Band Gap Switches for Standalone and Grid-Tied Applications
}

\author{
Yu-Chen Liu ${ }^{1, * \mathbb{D}}$, Ming-Cheng Chen ${ }^{2}$, Chun-Yu Yang ${ }^{2}$, Katherine A. Kim ${ }^{3}$ (D) \\ and Huang-Jen Chiu ${ }^{2}$ \\ 1 Department of Electrical Engineering, National Ilan University, No. 1, Section 1, Shennong Road, \\ Yilan 260, Taiwan \\ 2 Department of Electronic Engineering, National Taiwan University of Science and Technology, No. 43, \\ Section 4, Keelung Road, Da'an District, Taipei 106, Taiwan; d10202206@mail.ntust.edu.tw (M.-C.C.); \\ D9902212@mail.ntust.edu.tw (C.-Y.Y.); hjchiu@mail.ntust.edu.tw (H.-J.C.) \\ 3 School of Electrical and Computer Engineering, Ulsan National Institute of Science and Technology, \\ 50 UNIST-gil Ulju-gun, Ulsan 44919, Korea; kkim@unist.ac.kr \\ * Correspondence: ycliu@niu.edu.tw
}

Received: 6 February 2018; Accepted: 28 February 2018; Published: 6 March 2018

\begin{abstract}
An isolated photovoltaic micro-inverter for standalone and grid-tied applications is designed and implemented to achieve high efficiency. System configuration and design considerations, including the proposed active-clamp forward-flyback resonant converter for the DC-DC stage and a dual-frequency full-bridge inverter for the DC-AC stage, are analyzed and discussed. A prototype microinverter system is built and tested. Experimental results verify the feasibility of the proposed system, which achieves $95 \%$ power conversion efficiency at full load.
\end{abstract}

Keywords: photovoltaic; microinverter; grid-tied inverter; wide-band gap switches; high switching frequency; high power density; photovoltaic applications; power electronics; solar energy

\section{Introduction}

Photovoltaic (PV) energy systems have been extensively studied in research and industries as an alternative to fossil fuels to reduce greenhouse effects [1-3]. The concept of maximum power point tracking (MPPT) is used to extract maximum solar power from PV panels [4,5]. Several PV panels are typically connected in series/parallel to provide high voltage/current for high-power applications. However, PV panels frequently work under mismatched conditions due to partial shading and variations in panel orientation [6-8]. Thus, the power production of an entire PV string is reduced by this mismatching issue. One way to address the mismatch problem in large strings is to employ MPPT at the individual panel level using microinverters. Figure 1 shows the system diagram of the isolated PV microinverter mounted on each PV panel [9-11]. The pre-stage DC-DC converter provides isolation and controls the PV panel to extract its maximum power and provides a high-voltage DC bus for the post-stage DC-AC inverter [12-14]. The inverter converts the DC voltage into a sinusoidal AC output voltage that connects and supplies power to the AC-grid system [15]. 


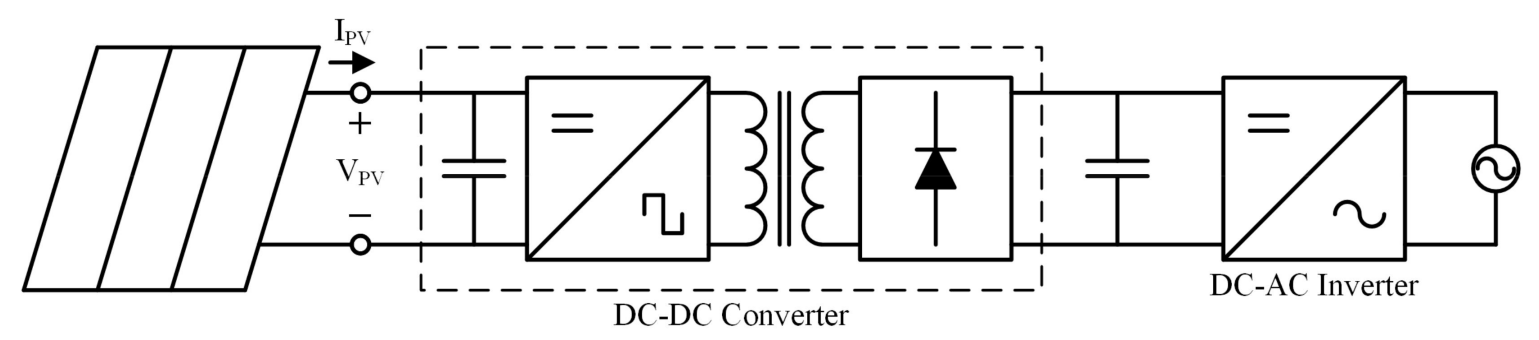

Figure 1. Power converter system diagram of an isolated photovoltaic (PV) microinverter system.

One problem with conventional solar microinverters is their poor conversion efficiency mainly attributed the hard-switching operation of the power converter. The commercial success of a PV microinverter depends on its reliability and efficiency. However, high device stress and hard switching operation results in low conversion efficiency. A PV microinverter with a pseudo DC-link is advantageous because it can achieve high efficiency. However, the component count and control complexity are high such that the overall system reliability is decreased [16-18].

Wide band-gap (WBG) materials such as Silicon Carbide (SiC) and Gallium Nitride (GaN) have attracted increasing attention in switching power supply applications [19-21]. Compared with the current Silicon (Si) technology, WBG devices provide significant advantages of high operating temperature, fast switching speed, and low on-resistance. Thus, they can reduce switching losses to enable high-frequency operation and achieve high-efficiency performance.

This work presents a highly efficient grid-tied isolated PV microinverter that can individually extract the maximum solar power to transfer power to the AC utility network. This work focuses on implementing a two-stage topology. The active-clamp forward-flyback converter topology is adopted for the front-end of the system, which converts energy from the PV panel to a higher voltage for the post-stage inverter. The proposed active-clamp forward-flyback converter topology combines the concepts of forward and flyback converters to increase the utilization of the flyback transformer, while the resonant mechanism is added to the converter unit design. The resonant aspect brings the benefits of extending the zero-voltage-switching (ZVS) region and allowing the secondary diodes to achieve zero-current-switching (ZCS). Furthermore, the fixed frequency pulse-width modulation (PWM) can be achieved to control the converter by only changing the component value. It retains the advantages of high efficiency and easy of control. The microinverter is implemented with WBG devices for PV panel applications to achieve low harmonic distortion, small circuit size and high efficiency. The contributions of this work are: (1) the introduction and analysis of the resonant control strategy of the active-clamp forward-flyback converter to allow for ZVC and ZCS to reduce losses, and (2) the implementation and experimental validation of the interleaved active-clamp forward-flyback converter using WBG devices to achieve a highly-efficiency PV microinverter.

\section{System Design and Considerations}

The proposed system configuration consists of an interleaved active-clamped forward-flyback converter for the DC-DC stage and a dual-frequency full-bridge inverter for the DCAC stage, as shown in Figure 2. The inverter can operate in a standalone mode (also called grid forming mode), where the inverter is not connected to the AC electric grid, or in an on-grid mode (also called grid feeding mode), where PV power is supplied to the AC electric grid [22]. The control of each converter differs depending on the operation mode, which is further detailed in Section 2.2. 


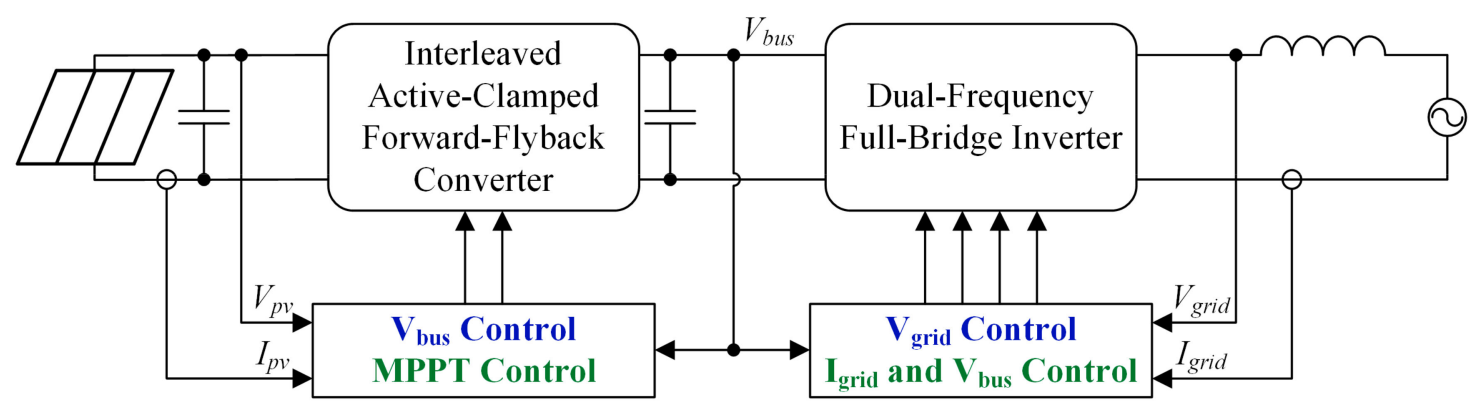

- Standalone Mode

— Grid-Tied Mode

Figure 2. Block diagram of the proposed microinverter system in standalone and on grid mode. MPPT, maximum power point tracking.

The detailed schematic of the interleaved active-clamped forward-flyback resonant converter and dual-frequency full-bridge circuit are shown in Figure 3. The first stage is the interleaved active-clamped forward-flyback resonant converter, whose characteristics are similar to those of forward resonant converter in the charging phase and the flyback resonant converter in the discharging phase. This topology has advantages of small size and low input current ripple. The active-clamped circuit is used to recycle energy stored by the leakage inductance of the coupled inductor and to reduce voltage stress on the switch. The DC-DC pre-stage circuit is operated in either single or interleaved mode depending on power conditions, which is used to improve light-load efficiency.

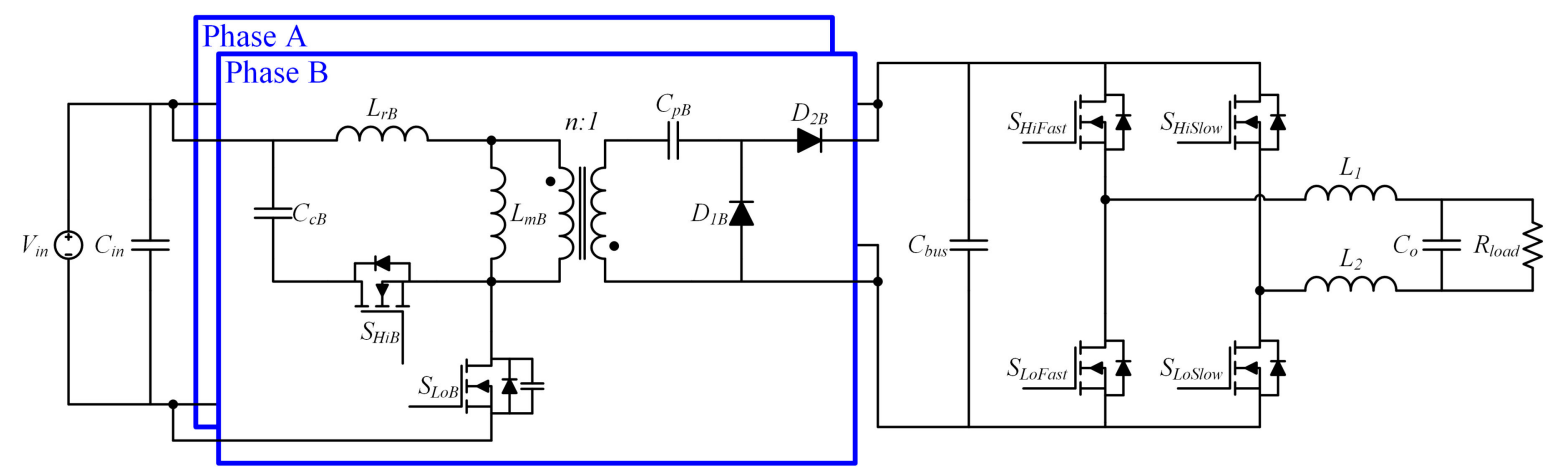

Figure 3. Circuit schematic of the DC-DC and DC-AC stages for the proposed microinverter system.

For the second stage, the dual-frequency full-bridge circuit is selected because it produces a wider output voltage range for the same input voltage and also reduces the current stress on the switch. The dual-frequency full-bridge circuit exhibits the important advantage of improved efficiency because of the single arm-chopped waveform action, as shown in Figure 4 . This feature nearly eliminates the switching loss on one arm. Details of the proposed microinverter system and control strategy are covered in the next section. 


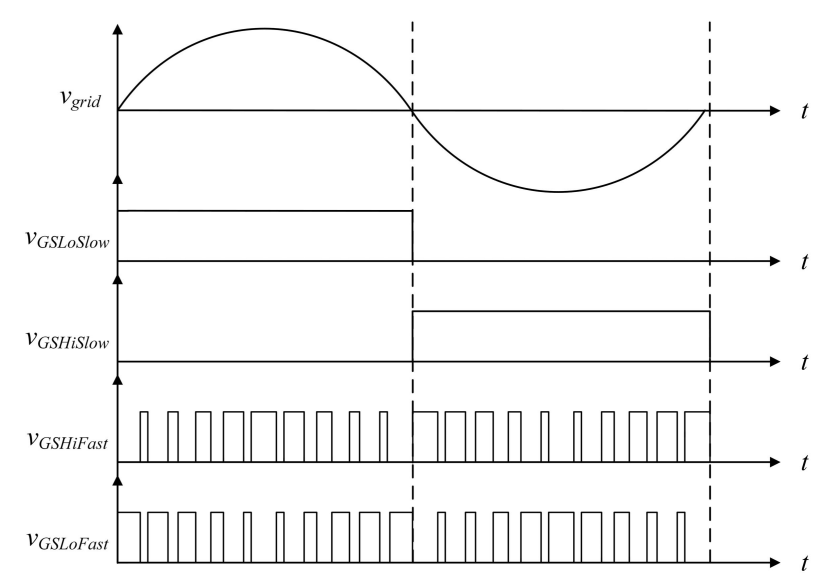

Figure 4. Theoretical waveforms of the dual-frequency full-bridge inverter.

\subsection{Active-Clamp Forward-Flyback Resonant Converter}

Under steady-state operation, the active-clamped forward-flyback resonant converter undergoes eight switching states. Figure $5 \mathrm{a}$ shows the circuit schematics and Figure $5 \mathrm{~b}$ shows the theoretical waveforms.

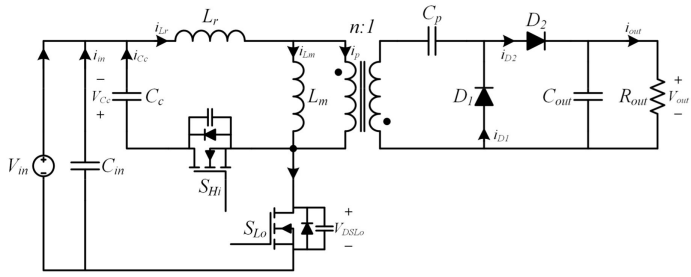

(a)

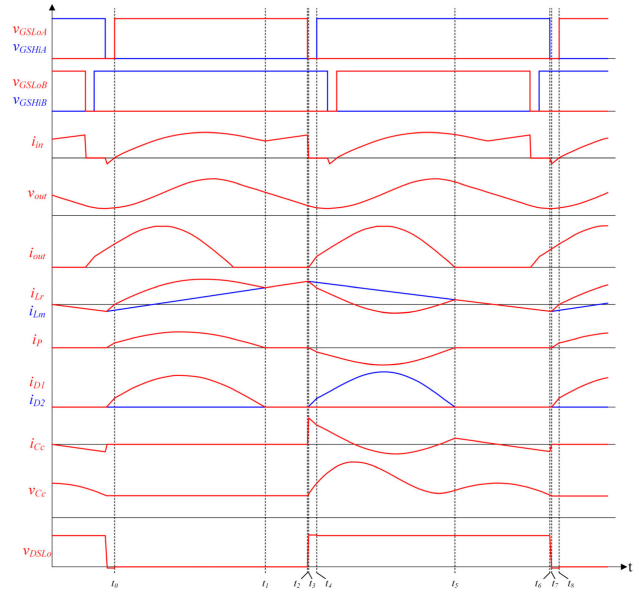

(b)

Figure 5. (a) Circuit schematic and (b) theoretical waveforms of the active-clamp forward-flyback resonant converter.

As shown in Figure 6, the circuit principles of the DC-DC converter stage are analyzed and discussed in detail. A capacitor is placed in parallel with the PV panel such that the PV voltage is relatively constant over the full cycle of the period. Thus, $V_{\text {in }}$ is assumed to be constant for the following analysis. Eight states are described for time $t$ over a full cycle.

State $1\left(t_{0}-t_{1}\right)$ : During this time interval, the auxiliary switch $S_{H i}$ is off. The main switch $S_{L o}$ is turned on with zero-voltage switching (ZVS) at $t_{0}$ because of the conduction of its body diode. At the secondary side, the diode $D_{1}$ is on and $D_{2}$ is off. Load power is supplied alone by the output capacitor $C_{\text {out }}$. The leakage inductance $L_{r}$ resonates with capacitor $C_{p}$. The resonant current $i_{L r}$ can be represented as follows:

$$
\begin{gathered}
i_{L r}(t)=i_{L m}(t)+i_{p}(t) \cong i_{L r}\left(t_{0}\right)+\frac{V_{\text {in }}}{L_{m}+L_{r}}\left(t-t_{0}\right)+i_{p}(t) \\
i_{p}(t)=\frac{V_{\text {in }}}{Z_{0}} \cdot \sin \omega_{0}\left(t-t_{0}\right)
\end{gathered}
$$


where $L_{m}$ is the magnetizing inductance and $i_{L m}$ is its current, $i_{p}$ is the primary transformer current, and $V_{i n}$ is the input voltage. Resonant angular frequency $\omega_{0}$ is defined as

$$
\omega_{0}=\frac{1}{\sqrt{L_{r} \cdot\left(C_{p} / n^{2}\right)}}
$$

where $n$ is the transformer turns ratio, and impedance $Z_{0}$ is defined as

$$
Z_{0}=\sqrt{\frac{L_{r}}{\left(C_{p} / n^{2}\right)}} .
$$

State $2\left(t_{1}-t_{2}\right)$ : The transformer primary current reaches zero at $t_{1}$, and the diode $D_{1}$ is off with zero-current switching (ZCS). During this time interval, $D_{2}$ remains turned off and the load power is still supplied only by output capacitor $C_{o u t}$. The resonant current $i_{L r}$ can be represented as follows:

$$
i_{L r}(t)=i_{L m}(t)=i_{L r}\left(t_{1}\right)+\frac{V_{i n}}{L_{m}+L_{r}}\left(t-t_{1}\right) .
$$

State $3\left(t_{2}-t_{3}\right)$ : The main switch $S_{L o}$ is turned off at $t_{2}$, and the equivalent inductor $\left(L_{m}+L_{r}\right)$ resonates with $S_{L o}$ D-S capacitor $C_{D S L o}$. The resonant current $i_{L r}$ and resonant voltage $v_{D S L o}$ can be represented as follows:

$$
\begin{gathered}
i_{L r}(t)=\frac{V_{\text {in }}}{Z_{2}} \cdot \sin \omega_{2}\left(t-t_{2}\right)+i_{L r}\left(t_{2}\right) \cdot \cos \omega_{2}\left(t-t_{2}\right) \\
v_{D S L o}(t) \cong V_{\text {in }} \cdot\left[1-\cos \omega_{2}\left(t-t_{2}\right)\right]+i_{L r}\left(t_{2}\right) \cdot Z_{2} \cdot \sin \omega_{2}\left(t-t_{2}\right)
\end{gathered}
$$

where resonant angular frequency $\omega_{2}$ is defined as

$$
\omega_{2}=\frac{1}{\sqrt{\left(L_{m}+L_{r}\right) \cdot C_{D S L o}}}
$$

and impedance $Z_{2}$ is defined as

$$
Z_{2}=\sqrt{\frac{\left(L_{m}+L_{r}\right)}{C_{D S L o}}} .
$$

State $4\left(t_{3}-t_{4}\right)$ : The resonant voltage $v_{D S L o}$ reaches $\left(V_{\text {in }}+v_{C}\right)$ at $t_{4}$, and the body diode of the auxiliary switch $S_{H i}$ and output diode $D_{2}$ are turned on. The resonant current $i_{L r}$, the transformer primary current $i_{p}$ and diode $D_{2}$ current $i_{D 2}$ can be represented as follows:

$$
\begin{gathered}
i_{L r}(t)=i_{L m}(t)+i_{p}(t) \cong i_{L m}\left(t_{3}\right)-\frac{v_{L m}(t)}{L_{m}}+i_{L r}\left(t_{3}\right) \cdot \cos \omega_{3}\left(t-t_{3}\right) \\
i_{p}(t) \cong i_{L r}\left(t_{3}\right) \cdot \cos \omega_{3}\left(t-t_{3}\right) \\
i_{D 2}(t)=n \cdot i_{p}(t)
\end{gathered}
$$

where resonant angular frequency $\omega_{3}$ is defined as

$$
\omega_{3}=\frac{1}{\sqrt{L_{r} \cdot C_{e q}}}
$$

equivalent capacitance $C_{e q}$ is defined as

$$
C_{e q}=\frac{C_{c} \cdot\left(C_{p} / n^{2}\right)}{C_{c}+\left(C_{p} / n^{2}\right)}
$$


and $C_{c}$ is the clamping capacitor.

State $5\left(t_{4}-t_{5}\right)$ : During this time interval, the main switch $S_{L o}$ remains turned off. The auxiliary switch $S_{H i}$ is turned on with ZCS at $t_{4}$. The circuit equations are the same with those during State 4 .

State $6\left(t_{5}-t_{6}\right)$ : The transformer primary current reaches zero at $t_{5}$. The output diode $D_{2}$ is turned off with ZCS and the load power is supplied only by the output capacitor $C_{\text {out }}$. The resonant current $i_{L r}$ is as follows:

$$
i_{L r}(t) \cong i_{L r}\left(t_{5}\right) \cos \omega_{5}\left(t-t_{5}\right)+\frac{v_{C_{C}}\left(t_{5}\right)}{Z_{5}} \cdot \sin \omega_{5}\left(t-t_{5}\right)
$$

where resonant angular frequency $\omega_{4}$ is defined as

$$
\omega_{5}=\frac{1}{\sqrt{\left(L_{r}+L_{m}\right) \cdot C_{c}}}
$$

and impedance $Z_{5}$ is defined as

$$
Z_{5}=\sqrt{\frac{\left(L_{r}+L_{m}\right)}{C_{c}}} .
$$

State $7\left(t_{6}-t_{7}\right)$ : The auxiliary switch $S_{H i}$ is turned off at $t_{6}$. During this time interval, the energy stored in $S_{L o}$ D-S capacitor $C_{D S L o}$ is released by the resonance with the equivalent inductor $\left(L_{m}+L_{r}\right)$. The resonant current $i_{L r}$ and voltage $v_{D S L o}$ can be represented as follows:

$$
\begin{gathered}
i_{L r}(t)=i_{L r}\left(t_{6}\right) \cos \omega_{6}\left(t-t_{6}\right)+\frac{\left[V_{i n}-v_{D S L o}\left(t_{6}\right)\right]}{Z_{6}} \cdot \sin \omega_{6}\left(t-t_{6}\right) \\
v_{D S L o}(t)=V_{i n}-\left[V_{i n}-v_{D S L o}\left(t_{6}\right)\right] \cos \omega_{6}\left(t-t_{6}\right)+i_{L r}\left(t_{6}\right) \cdot Z_{6} \cdot \sin \omega_{6}\left(t-t_{6}\right)
\end{gathered}
$$

where resonant angular frequency $\omega_{6}$ is defined as

$$
\omega_{6}=\frac{1}{\sqrt{\left(L_{r}+L_{m}\right) \cdot C_{D S L o}}}
$$

and impedance $Z_{6}$ is defined as

$$
Z_{6}=\sqrt{\frac{L_{r}+L_{m}}{C_{D S L o}}} .
$$

State $8\left(t_{7}-t_{8}\right)$ : The resonant voltage $v_{D S L o}$ is reduced to zero at $t_{7}$ and the body diode of the main switch $S_{L o}$ conducts to achieve ZVS. The resonant current $i_{L r}$ is as follows:

$$
i_{L r}(t)=i_{L r}\left(t_{7}\right)+\frac{V_{i n}}{L_{r}+L_{m}}\left(t-t_{7}\right)
$$

After completing one switching period, the operation mode starts over from State 1 . The detailed resonant waveforms are depicted in Figure 7. The ZCS conditions for diode $D_{1}$ is

$$
T_{o n, 1}>1 / 2 f_{r, 1}=\pi \sqrt{L_{r}\left(\frac{C_{p}}{n^{2}}\right)}
$$

and the ZCS conditions for $D_{2}$ is

$$
T_{o n, 2}>1 / 2 f_{r, 2}=\pi \sqrt{L_{r}\left(\frac{C_{c} * C_{p} / n^{2}}{C_{c}+C_{p} / n^{2}}\right)}
$$


where $T_{o n, 1}$ is the turn on time of $S_{L o}$ and $f_{r, 1}$ is its associated resonant frequency, and $T_{o n, 2}$ is the turn on time of $S_{H i}$ and $f_{r, 2}$ is its associated resonant frequency.

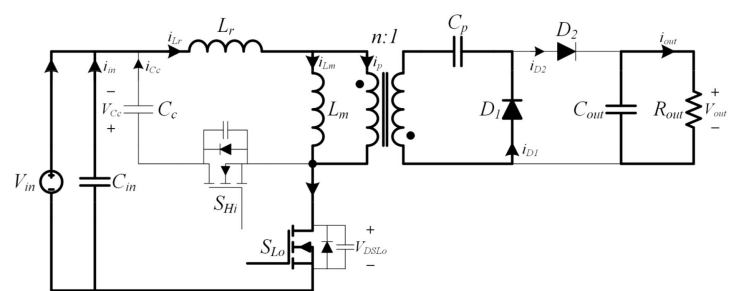

(a) $t_{0} \sim t_{1}$

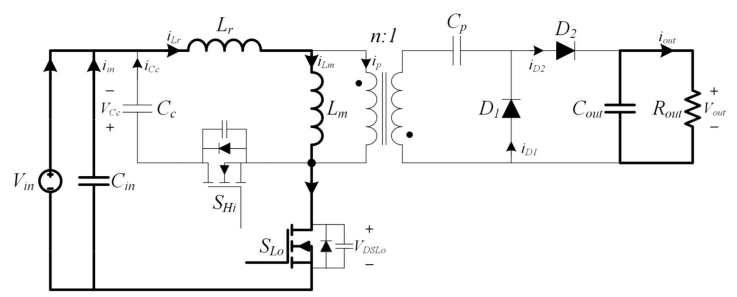

(b) $t_{1} \sim t_{2}$

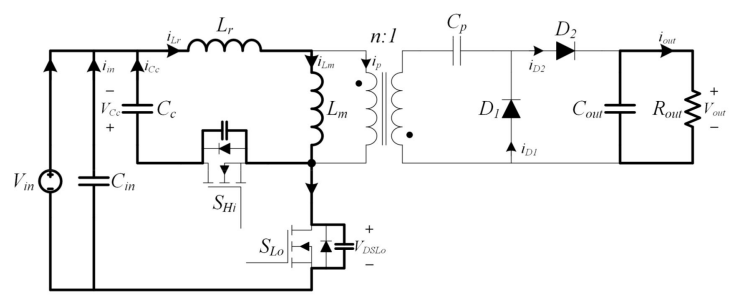

(c) $t_{2} \sim t_{3}$

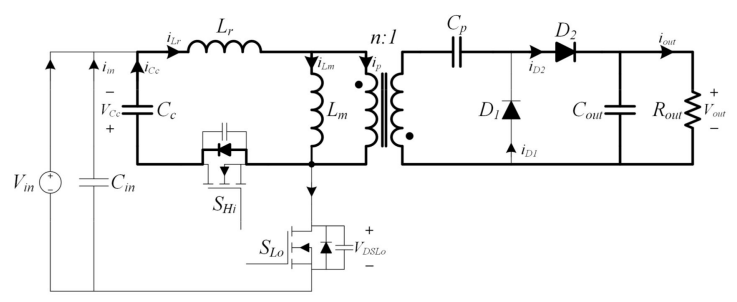

(d) $t_{3} \sim t_{4}$

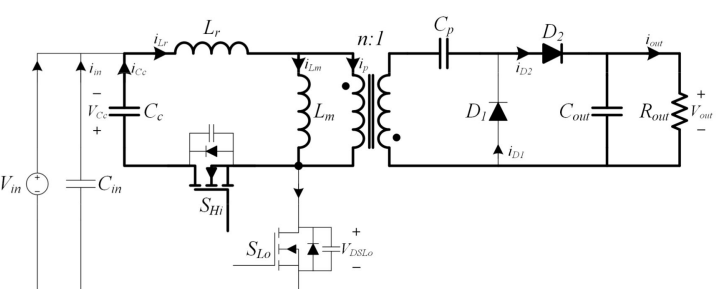

(e) $t_{f^{\prime}} \sim t_{5}$

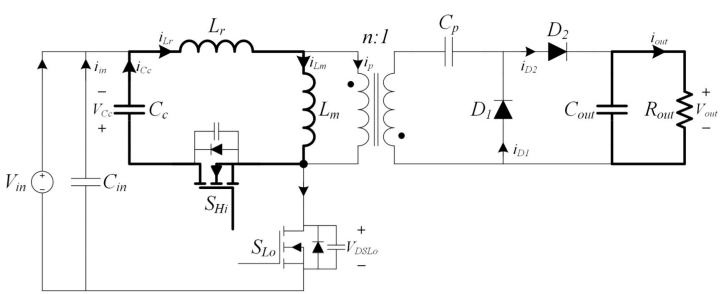

(f) $t_{5} \sim t_{6}$

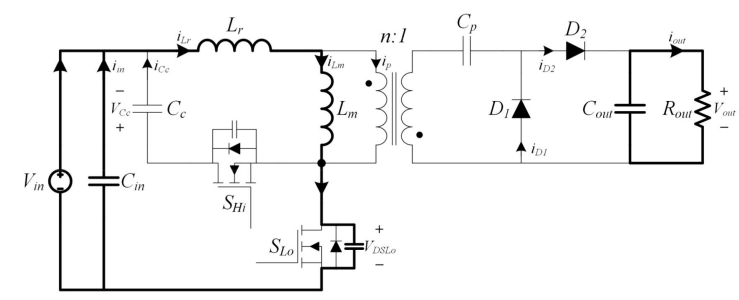

(g) $t_{6} \sim t_{7}$

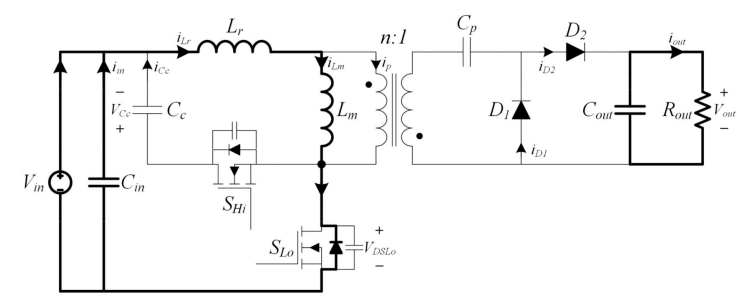

(h) $t_{7} \sim t_{8}$

Figure 6. Switching states of the active-clamped forward-flyback resonant converter.

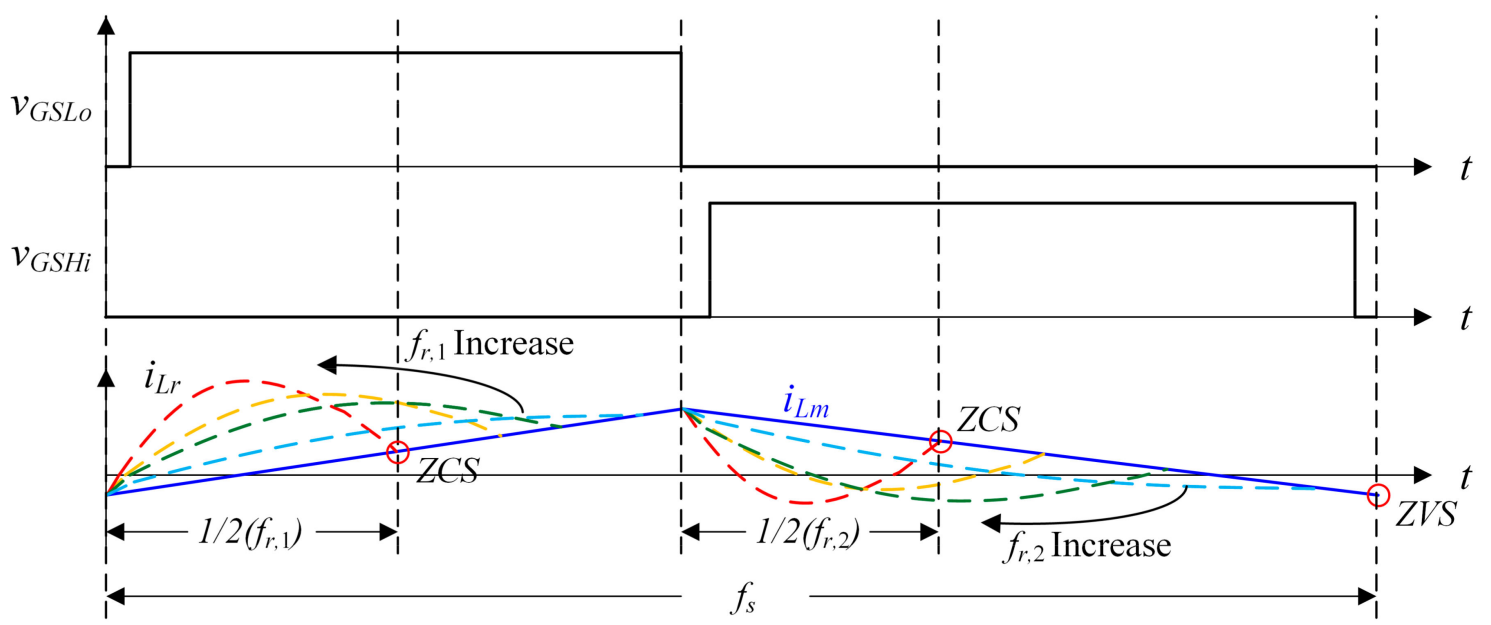

Figure 7. Detailed resonant waveform of the converter. 


\subsection{System Control}

The microinverter used in this study has two operation modes: standalone and grid-tied operation. The system will automatically detect which mode to use. If the microinverter detects no voltage at the output terminal upon start-up, then it will operate in standalone mode. However, if a voltage is detected, then the microinverter will attempt to start the grid-tied mode operation. The control flowchart is shown in Figure 8.

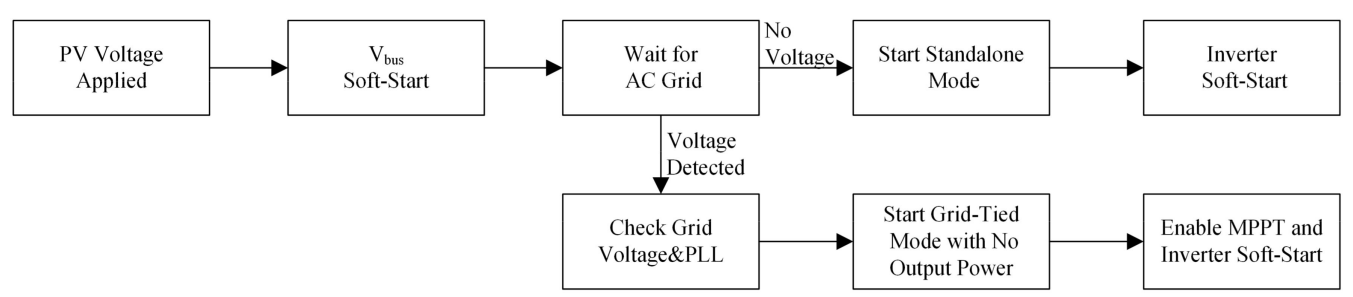

Figure 8. Control flowchart of the proposed microinverter system.

In the standalone mode, the amount of power to be extracted from the solar panel is determined by the load demand. Therefore, the inverter and DC-DC stages will only be responsible for maintaining the correct voltage. The inverter will be in voltage-mode feedback, which ensures that the output voltage is a correctly-shaped sine wave with the correct amplitude. The voltage loop on the inverter stage uses proportional-resonant (PR) control to provide sufficient gain at $60 \mathrm{~Hz}$ output frequency. In this mode, it is particularly important to ensure good voltage regulation and low total harmonic distortion (THD). Meanwhile, the DC-DC stage regulates the bus voltage to ensure that the inverter has the correct voltage to work with. The block diagrams for the control in standalone mode for the DC-DC stage and DC-AC inverter stage are shown in Figure 9.

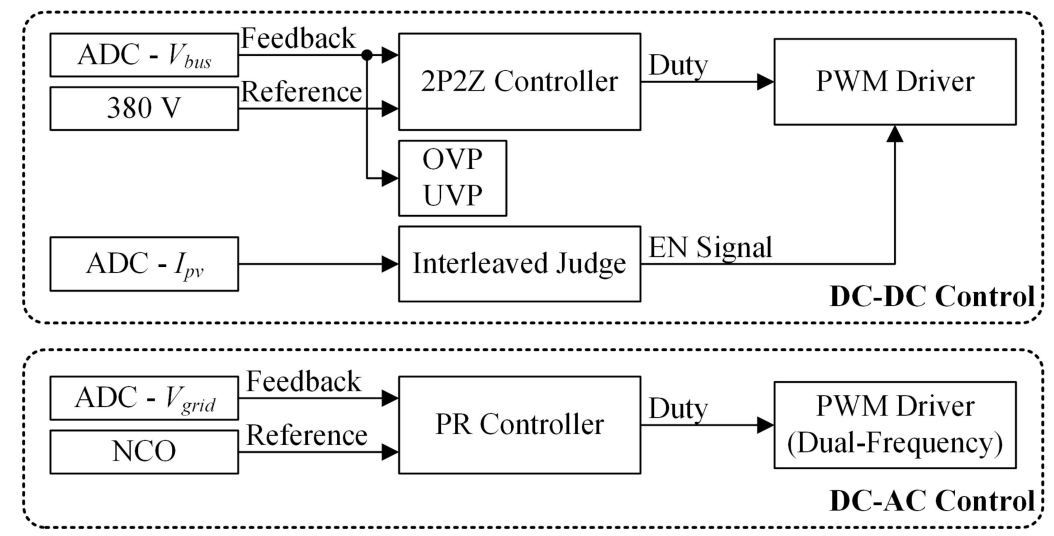

Figure 9. Control block diagram for the DC-DC stage and inverter in standalone mode. ADC, analog to digital converter; OVP, over voltage protection; UVP, under voltage protection; $2 \mathrm{P} 2 \mathrm{Z}, 2$ pole 2 zero; EN, interleaved enable signal; PWM, pulse-width modulation; NCO, numerically controlled oscillator; PR, proportional-resonant.

In the grid-tied mode, the unit decides how much power it will deliver to the grid. The duty of the DC-DC stage is to implement MPPT controller. The controller will attempt to deliver maximum power to the DC bus regardless of the bus voltage. Therefore, the inverter side has the task of maintaining the bus voltage. The inverter will have to deliver the same amount of power delivered to the bus to maintain the bus voltage at a constant value. The output voltage in grid-tied mode is dictated by the AC grid voltage; hence, the inverter will control the amount of current pumped into the grid. A feedback control loop is used for the inverter to achieve the current dictated by the reference. 
The grid-tied inverter requires that a sine wave with the same phase as the grid voltage be pumped into the grid. Thus, the input to the reference of the current loop is a numerically controlled oscillator (NCO). However, similar to the standalone mode, the gain at the AC-line frequency must be sufficient to ensure that the output follows the reference with accuracy. Thus, a PR control strategy is also implemented for the inverter's current loop in grid-tied mode. The regulation requires that the output current signal must be in phase with the grid voltage. Therefore, certain mechanisms are necessary to produce a sine wave that is in phase with the output voltage. Accordingly, a phase-locked loop (PLL) that uses a phase detector is used to detect the phase difference between the output and input signals of the NCO. The phase difference is then fed through a controller, which will produce an output frequency signal given to the NCO. Consequently, a feedback loop in frequency is formed, which forces the NCO frequency to follow that of the grid voltage signal, as shown in Figure 10.

In addition to the PLL and current loop, the bus voltage must be kept at a constant value. This regulation task is handled by the inverter, which varies the current signal in order to control the voltage at the bus. A perturb and observe (P\&O) method, which exhibits the benefits of simplicity and good performance, is adopted to realize MPPT for the DC-DC stage operated in grid-tied mode. The control black diagram for the DC-DC stage is also shown in Figure 10.
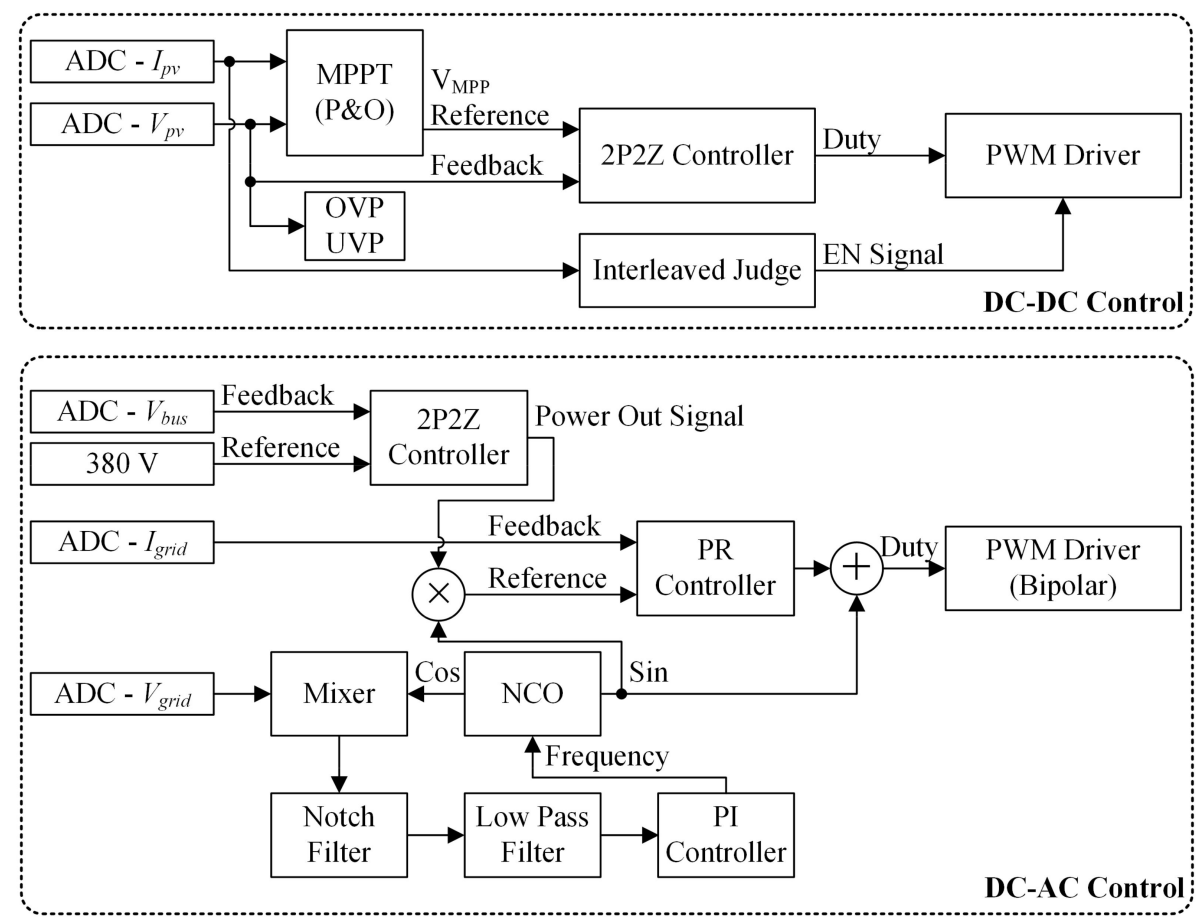

Figure 10. Control block diagram for the DC-DC stage and inverter in grid-tied mode.

\section{Results}

\subsection{Power Switch Comparison}

GaN switches provide significant advantages over silicon (Si) metal oxide semiconductor field effect transistors (MOSFETs) with lower gate charge, smaller reverse recovery charge, and faster switching speeds. As outlined in Table 1, the GaN high electron mobility transistor (HEMT) presents much lower Figure of Merit (FOM), which is better than the conventional CoolMOS device. With much lower gate-charge $\mathrm{Q}_{\mathrm{g}}$, the switching speed of the GaN HEMT device is much faster. Figure 11 shows the measured switching waveforms of Infineon CoolMOS 20N60CFD and Transphorm GaN HEMT TPH3006PS with Silicon Labs gate driver Si8261 and a $0-\Omega$ gate resistor. In this work, 20 N60CFD and TPH3006PS were tested and compared as high-frequency switches of the inverter stage. Figure 12 
shows the gate driver circuit for the GaN HEMT power switches in the experiments. Due to the consideration of a lower $V_{g s}$ threshold voltage to turn the switch fully on, negative-voltage driving is provided during switch-off time to increase noise immunity. As GaN switches operate with low rise and fall times, parasitic inductances and capacitances in the printed circuit board (PCB) layout must be minimized to avoid excessive ringing in the circuit [20].

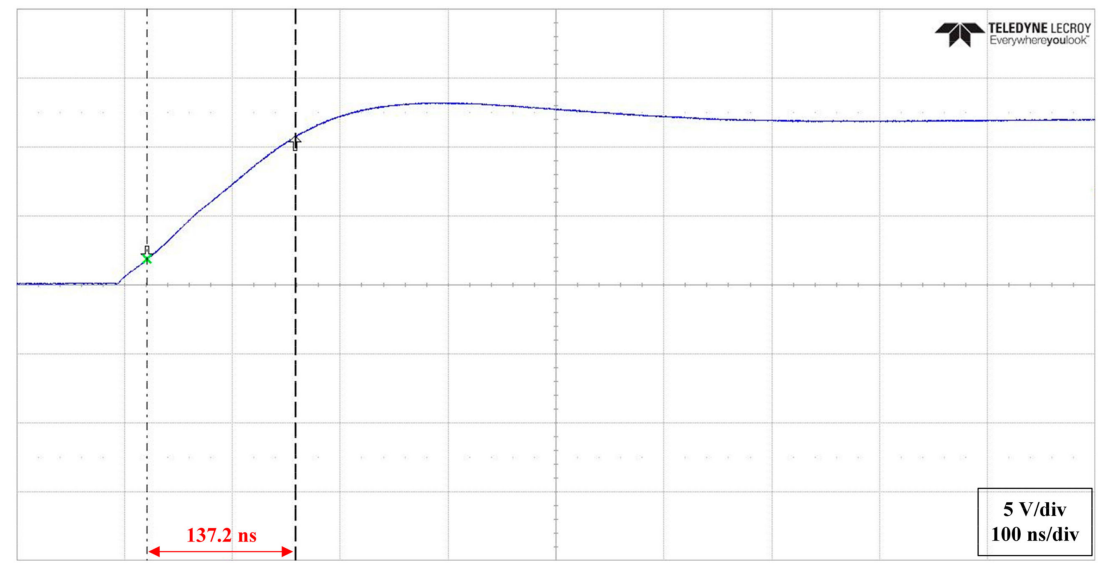

(a)

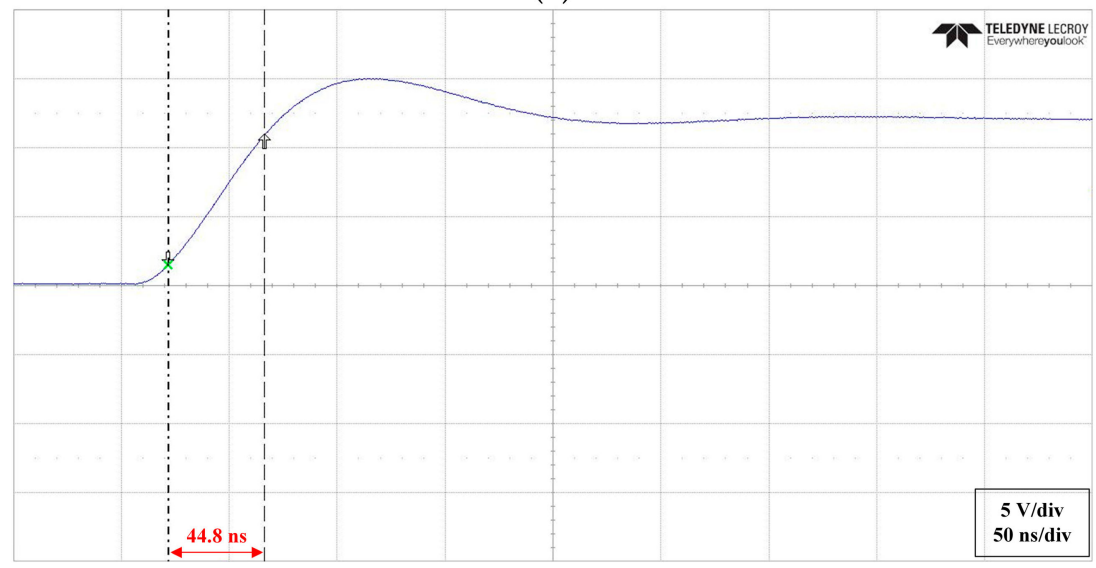

(b)

Figure 11. Switching waveforms of the (a) CoolMOS 20N60CFD and (b) GaN HEMT TPH3006PS.

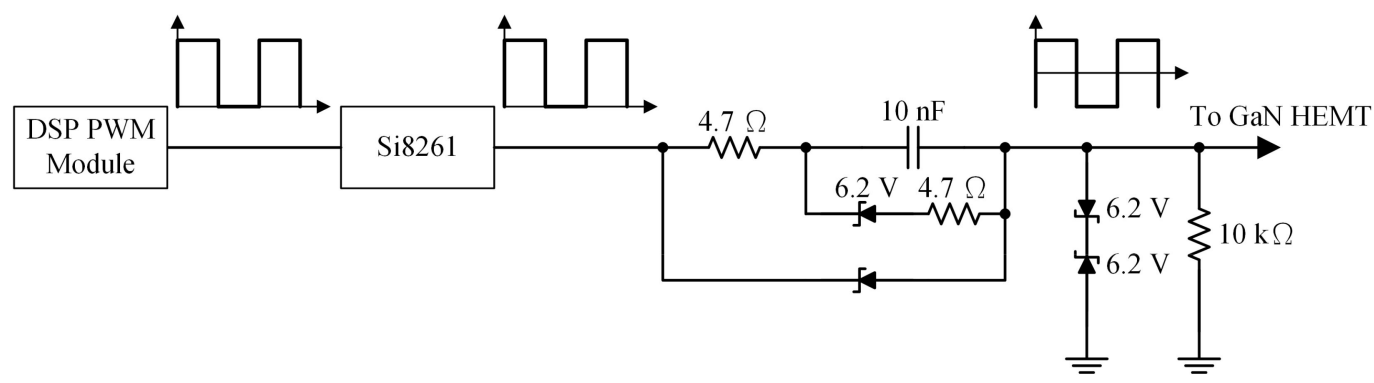

Figure 12. Gate driver circuit for the GaN HEMT power switches.

Table 1. Parameter of GAN HEMT and COOLMOS Devices.

\begin{tabular}{cccc}
\hline Device & On-Resistance $(\boldsymbol{\Omega})$ & Gate-Charge $(\mathbf{n C})$ & FOM \\
\hline GaN HEMT TPH3006PS & 0.15 & 6.2 & 0.93 \\
CoolMOS 20N60CFD & 0.19 & 95 & 18.05 \\
\hline
\end{tabular}




\subsection{Experimental Verification}

A 500-W microinverter was designed and implemented for both standalone and grid-tied applications. The specifications of the prototype are listed in Table 2. A photograph of the developed prototype system is shown in Figure 13. In the experimental setup, the PV input was a Chroma PV simulator $62150 \mathrm{H}-1000 \mathrm{~S}$.

Table 2. Circuit Specifications for the microinverter experimental prototype.

\begin{tabular}{ccc}
\hline Parameter & Symbol & Specification \\
\hline Input voltage & $V_{i n}$ & $18-40 \mathrm{~V}$ \\
Output voltage & $V_{o}$ & $240 \mathrm{~V}_{\mathrm{rms}}$ \\
Output current & $I_{o}$ & $2.1 \mathrm{~A}_{\text {rms }}$ (rated) \\
Efficiency & $\eta$ & $\geq 0.95$ (at $375 \mathrm{~W})$ \\
Voltage THD & $\mathrm{THD}_{\mathrm{v}}$ & $\leq 5 \%$ (at nominal output) \\
\hline
\end{tabular}
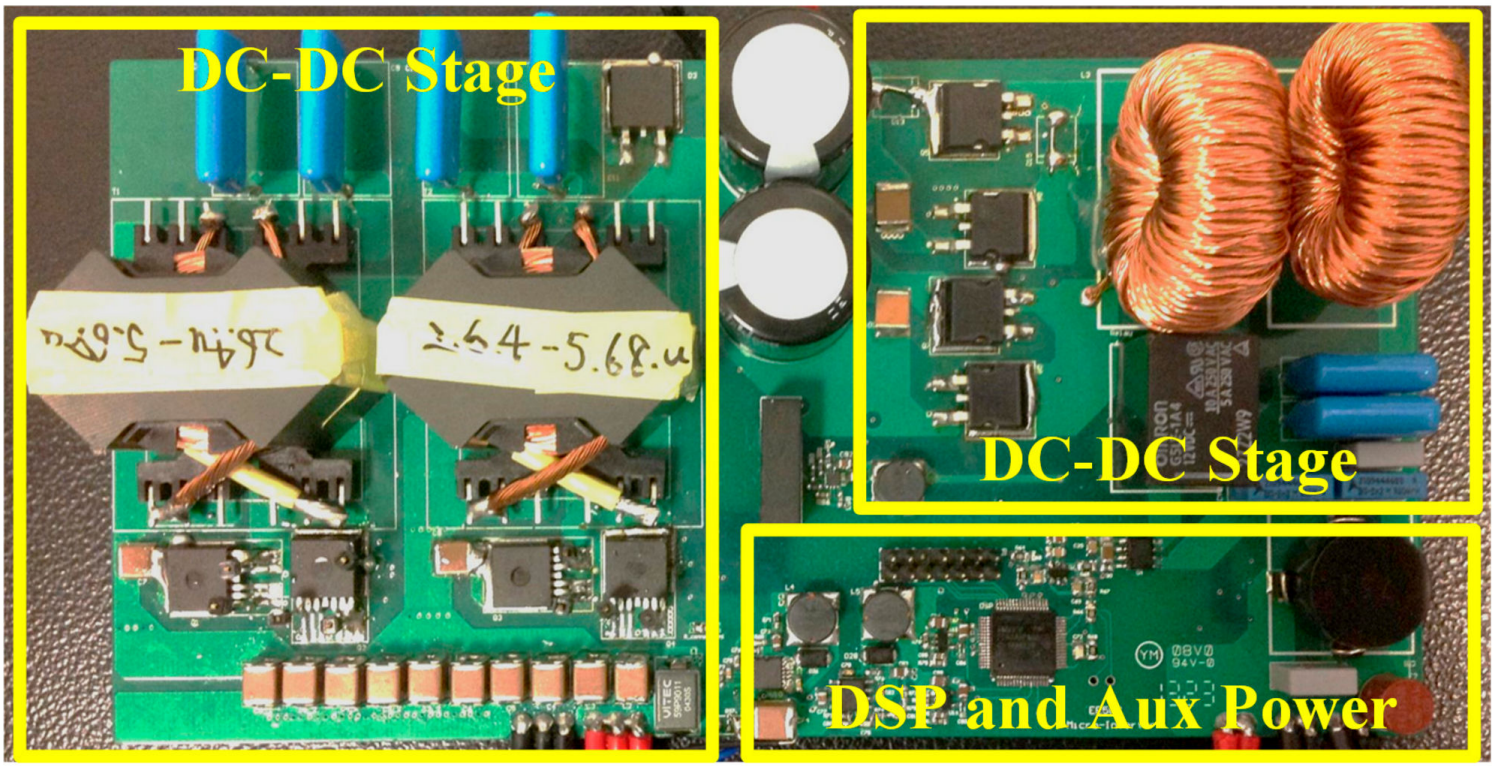

Figure 13. Photograph of the 500-W Microinverter experimental prototype.

In the prototype system, several wide band-gap devices were used and tested to improve the efficiency performance. For the interleaved active-clamped forward-flyback converter stage, the CREE $\mathrm{SiC}$ diode C3D10060 was used to reduce reverse-recovery loss on the secondary diodes. Infineon CoolMOS 20N60CFD and Transphorm GaN HEMT TPH3006PS were tested and compared in the experiments for high-frequency switches of the inverter stage. Approximately $1 \%$ improvement for CEC efficiency can be achieved using GaN HEMT, compared with the results using CoolMOS.

Figure 14 shows the measured gating signals for the DC-DC stage. The converter is operated in single mode at low power levels, as shown in Figure 14a, or interleaved mode, as shown in Figure 14b. The operation mode is changed during operation, depending on the power conditions. The resonant frequencies $f_{r, 1}$ and $f_{r, 2}$ are $66 \mathrm{kHz}$ and $95 \mathrm{kHz}$, respectively. Figure 15 show the measured resonant current and soft-switching waveforms, which are consistent with the theoretical waveforms shown in Figure $5 \mathrm{~b}$. Figure 16 shows the voltage and current waveforms of the power switches, which show that the converter achieves ZVS and ZCS. The efficiency performance of the DC-DC stage, which reaches an efficiency of $97 \%$, is shown in Table 3 . 


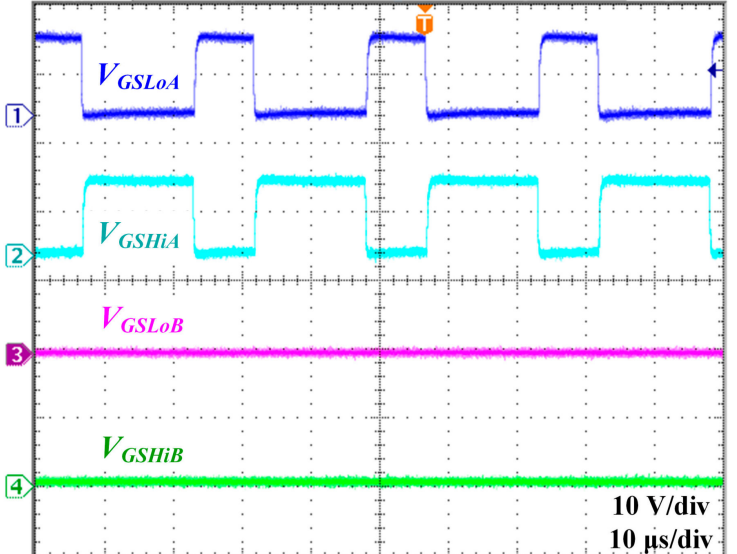

(a)

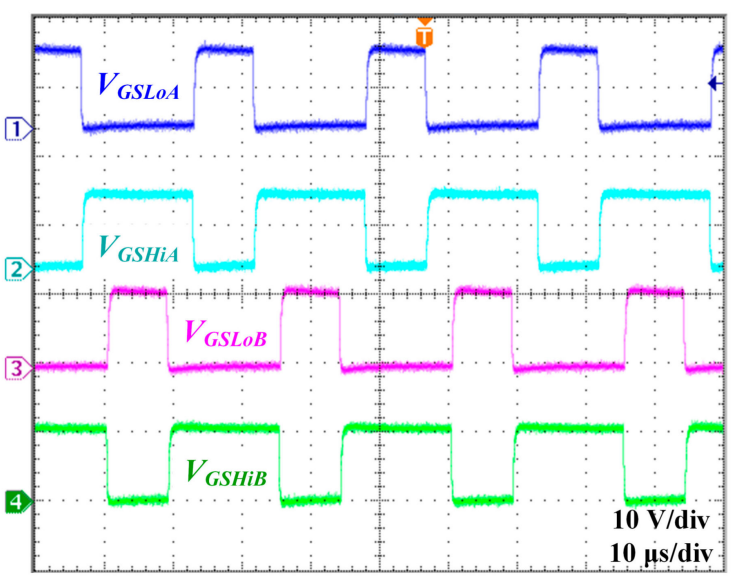

(b)

Figure 14. Waveforms of the gating signals for the DC-DC stage in (a) single and (b) interleaved modes.

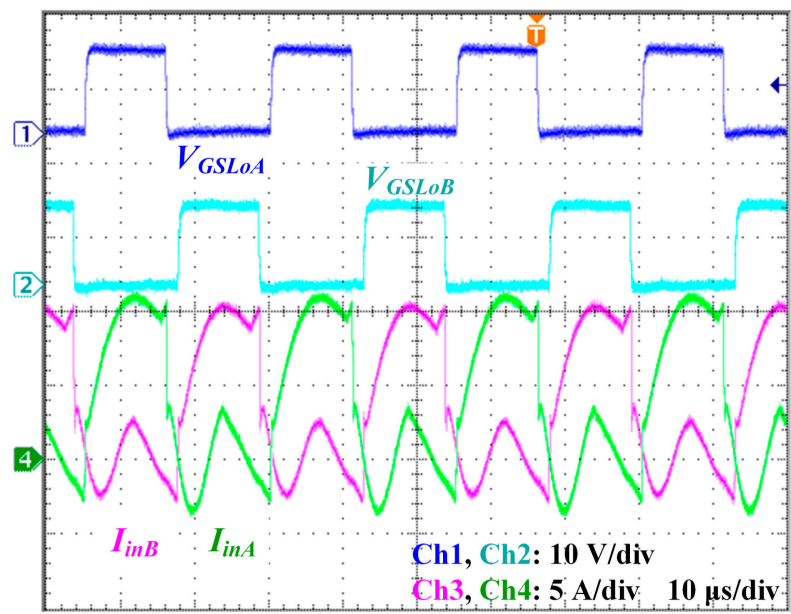

Figure 15. Gate and resonant current waveforms of the resonant converter.

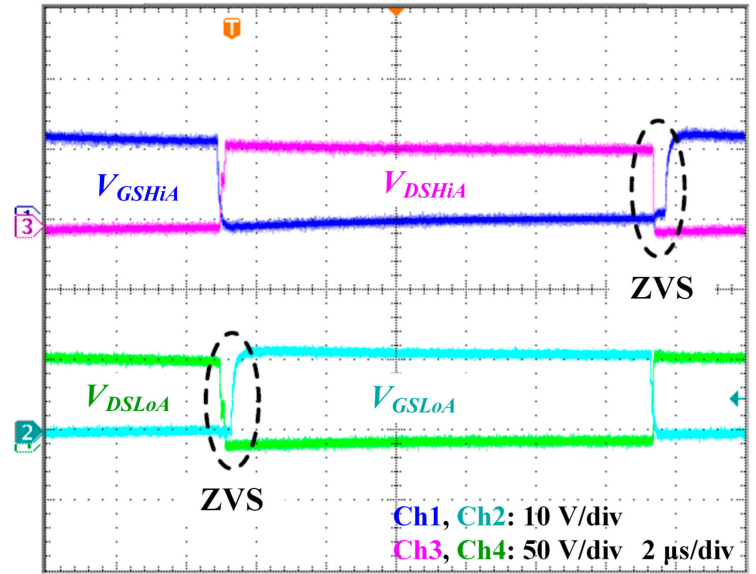

(a)

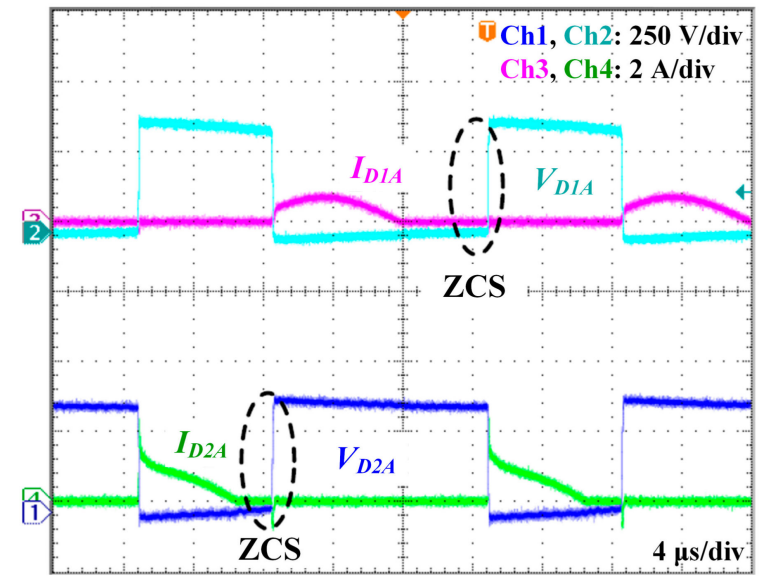

(b)

Figure 16. Waveforms of the switches showing (a) zero-voltage switching (ZVS) and (b) zero-current switching (ZCS) achieved in the circuit. 
Table 3. Experimental results for the DC-DC stage.

\begin{tabular}{ccc}
\hline Mode & $\boldsymbol{P}_{\boldsymbol{o}}(\mathbf{W})$ & Efficiency $(\mathbf{\%})$ \\
\hline single & 100 & 97.10 \\
interleaved & 250 & 97.25 \\
interleaved & 375 & 97.10 \\
interleaved & 500 & 96.50 \\
\hline
\end{tabular}

Figure 17 shows the switching waveforms of the dual-frequency full-bridge DC-AC inverter under a 250-W condition, which demonstrates the single-arm switching feature. Table 4 shows the measured efficiency performance under different power conditions. The efficiency reaches $98 \%$ at full load.

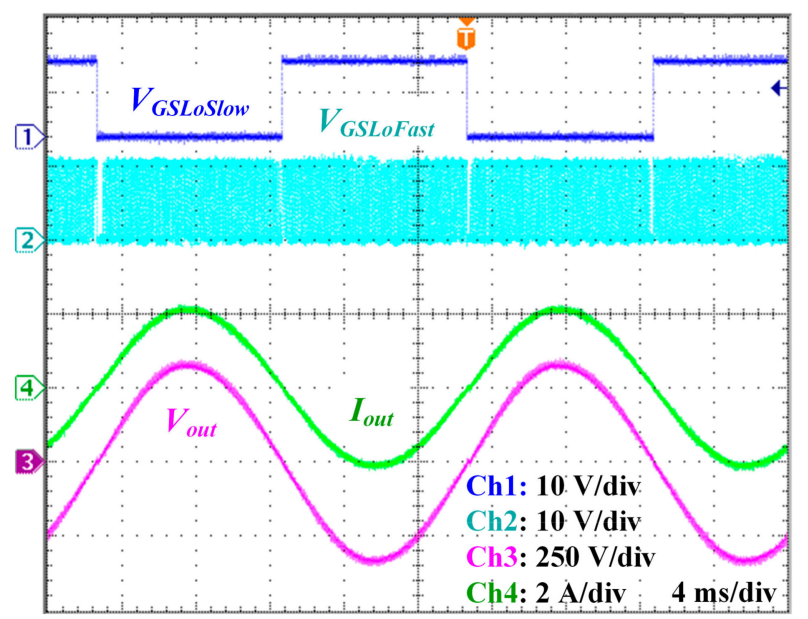

Figure 17. Measured waveforms for the inverter stage of the microinverter.

Table 4. Experimental results for the dual-frequency full-bridge inverter stage.

\begin{tabular}{cccc}
\hline$V_{\text {bus }}(\mathrm{V})$ & $\boldsymbol{V}_{\boldsymbol{o}}\left(\mathrm{V}_{\text {rms }}\right)$ & $\boldsymbol{P}_{\boldsymbol{o}}(\mathrm{W})$ & Efficiency $(\%)$ \\
\hline 380 & 240 & 100 & 96.65 \\
380 & 240 & 250 & 97.80 \\
380 & 240 & 375 & 98.00 \\
380 & 240 & 500 & 98.15 \\
\hline
\end{tabular}

Table 5 shows the measured overall efficiency of the 500-W microinverter system under an input voltage of $34 \mathrm{~V}$ and an output voltage $V_{o}$ of $240 \mathrm{~V}_{\text {rms }}$. In the grid-tied mode, experimental results showed that the maximum power point was tracked with an accuracy of approximately $99 \%$. The power efficiency of the microinverter system reaches $95 \%$ and maintains high efficiency over the full power range.

Table 5. Experimental results for the full 500-W microinverter system.

\begin{tabular}{cccc}
\hline$V_{\boldsymbol{p} v}(\mathrm{~V})$ & $\boldsymbol{V}_{\boldsymbol{o}}\left(\mathrm{V}_{\mathbf{r m s}}\right)$ & $\boldsymbol{P}_{\boldsymbol{o}}(\mathbf{W})$ & Efficiency $(\%)$ \\
\hline 34 & 240 & 100 & 94.15 \\
34 & 240 & 250 & 95.25 \\
34 & 240 & 375 & 95.17 \\
34 & 240 & 500 & 94.70 \\
\hline
\end{tabular}




\section{Conclusions}

An isolated PV microinverter was studied for standalone and grid-tied applications. An interleaved active-clamp forward-flyback resonant converter was used as the isolated DC-DC converter stage and dual-frequency full-bridge inverter was used as the DC-AC conversion stage was used to achieve high efficiency and reliability of the microinverter. The control algorithm of the microinverter was described for startup, standalone mode, and grid-tied mode. Wide band-gap devices were also used and compared with conventional Si-based devices in the experiments, and GaN switches were selected for the final design. The experimental verifications showed that the prototype system exhibited high efficiency and high MPPT accuracy, reaching 95\% for the overall microinverter system.

Acknowledgments: This research was supported by the National Science Council of Taiwan under Grant MOST 105-2218-E-197-002 and MOST 106-2221-E-197-015, and the Basic Science Research Program through the National Research Foundation of Korea funded by the Ministry of Education (2016R1D1A1B03931573).

Author Contributions: Yu-Chen Liu, Ming-Cheng Chen, Chun-Yu Yang, and Huang-Jen Chiu conceived and designed the prototype and experiments; Ming-Cheng Chen and Chun-Yu Yang performed the experiments; Yu-Chen Liu, Ming-Cheng Chen, Chun-Yu Yang, and Katherine A. Kim analyzed the data; Huang-Jen Chiu contributed equipment/materials/analysis tools; Yu-Chen Liu, Ming-Cheng Chen, Katherine A. Kim, and Huang-Jen Chiu wrote the paper.

Conflicts of Interest: The authors declare no conflict of interest. The founding sponsors had no role in the design of the study; in the collection, analyses, or interpretation of data; in the writing of the manuscript; and in the decision to publish the results.

\section{References}

1. Paz, F.; Ordonez, M. High-performance solar MPPT using switching ripple identification based on a lock-in amplifier. IEEE Trans. Ind. Electron. 2016, 63, 3595-3604. [CrossRef]

2. Debnath, D.; Chatterjee, K. Two-stage solar photovoltaic-based stand-alone scheme having battery as energy storage element for rural deployment. IEEE Trans. Ind. Electron. 2015, 62, 4148-4157. [CrossRef]

3. Sahan, B.; Vergara, A.N.; Henze, N.; Engler, A.; Zacharias, P. A single-stage PV module integrated converter based on a low-power current-source inverter. IEEE Trans. Ind. Electron. 2008, 55, 2602-2609. [CrossRef]

4. Suntio, T.; Leppaaho, J.; Huusari, J.; Nousiainen, L. Issues on Solar-Generator Interfacing With Current-Fed MPP-Tracking Converters. IEEE Trans. Power Electron. 2010, 25, 2409-2419. [CrossRef]

5. Huusari, J.; Suntio, T. Dynamic Properties of Current-Fed Quadratic Full-Bridge Buck Converter for Distributed Photovoltaic MPP-Tracking Systems. IEEE Trans. Power Electron. 2012, 27, 4681-4689. [CrossRef]

6. Femia, N.; Lisi, G.; Petrone, G.; Spagnuolo, G.; Vitelli, M. Distributed maximum power point tracking of photovoltaic arrays: Novel approach and system analysis. IEEE Trans. Ind. Electron. 2008, 55, 2610-2621. [CrossRef]

7. Khan, O.; Xiao, W.; Zeineldin, H.H. Gallium-nitride-based submodule integrated converters for high-efficiency distributed maximum power point tracking PV applications. IEEE Trans. Ind. Electron. 2016, 63, 966-975. [CrossRef]

8. Vázquez, M.J.V.; Márquez, J.M.A.; Manzano, F.S. A methodology for optimizing stand-alone PV-system size using parallel-connected DC/DC converters. IEEE Trans. Ind. Electron. 2008, 55, 2664-2673. [CrossRef]

9. Killi, M.; Samanta, S. An adaptive voltage-sensor-based MPPT for photovoltaic systems with SEPIC converter including steady-state and drift analysis. IEEE Trans. Ind. Electron. 2015, 62, 7609-7619. [CrossRef]

10. Xiao, W.; Ozog, N.; Dunford, W.G. Topology study of photovoltaic interface for maximum power point tracking. IEEE Trans. Ind. Electron. 2007, 54, 1696-1704. [CrossRef]

11. Lin, F.J.; Chiang, H.C.; Chang, J.K. Modeling and Controller Design of PV Micro Inverter without Using Electrolytic Capacitors and Input Current Sensors. Energies 2016, 9, 993. [CrossRef]

12. Nousiainen, L.; Puukko, J.; Mäki, A.; Messo, T.; Huusari, J.; Jokipii, J.; Viinamäki, J.; Lobera, D.T.; Valkealahti, S.; Suntio, T. Photovoltaic Generator as an Input Source for Power Electronic Converters. IEEE Trans. Power Electron. 2013, 28, 3028-3038. [CrossRef]

13. Suntio, T.; Messo, T.; Aapro, A.; Kivimäki, J.; Kuperman, A. Review of PV Generator as an Input Source for Power Electronic Converters. Energies 2017, 10, 1076. [CrossRef] 
14. Zapata, J.W.; Kouro, S.; Carrasco, G.; Renaudineau, H. Step-Up Partial Power DC-DC Converters for Two-Stage PV Systems with Interleaved Current Performance. Energies 2018, 11, 357. [CrossRef]

15. Suntio, T.; Messo, T.; Puukko, J. Power Electronic Converters: Dynamics and Control in Conventional and Renewable Energy Applications; Wiley: Weinheim, Germany, 2017; ISBN 978-3-527-34022-4.

16. Park, J.H.; Ahn, J.Y.; Cho, B.H.; Yu, G.J. Dual-module-based maximum power point tracking control of photovoltaic systems. IEEE Trans. Power Electron. 2006, 53, 1036-1047. [CrossRef]

17. Sree, K.R.; Rathore, A.K. Hybrid modulated extended secondary universal current-fed ZVS converter for wide voltage range: Analysis, design, and experimental results. IEEE Trans. Power Electron. 2015, 62, 4471-4480. [CrossRef]

18. Mutoh, N.; Inoue, T. A control method to charge series-connected ultraelectric double-layer capacitors suitable for photovoltaic generation systems combining MPPT control method. IEEE Trans. Power Electron. 2007, 54, 374-383. [CrossRef]

19. Chakraborty, C.; Iu, H.H.C.; Lu, D.D.C. Power converters, control, and energy management for distributed generation. IEEE Trans. Power Electron. 2015, 62, 4466-4470. [CrossRef]

20. Huang, Z.; Recht, F.; Wu, Y. PCB Layout and Probing for GaN Power Switches; Application Note AN-0003, Rev. 2; Transphorm Inc.: Goleta, CA, USA, 2015.

21. Kolar, J.; Krismer, F.; Lobsiger, Y.; Muhlethaler, J.; Nussbaumer, T.; Minibock, J. Extreme efficiency power electronics. In Proceedings of the International Conference on Integrated Power Electronics Systems (CIPS), Nuremberg, Germany, 6-8 March 2012; pp. 1-22.

22. Viinamäki, J.; Kuperman, A.; Suntio, T. Grid-Forming-Mode Operation of Boost-Power-Stage Converter in PV-Generator-Interfacing Applications. Energies 2017, 10, 1033. [CrossRef]

(C) 2018 by the authors. Licensee MDPI, Basel, Switzerland. This article is an open access article distributed under the terms and conditions of the Creative Commons Attribution (CC BY) license (http:/ / creativecommons.org/licenses/by/4.0/). 